\title{
Value of Adding Cisternostomy to Decompressive Hemicraniectomy in the Management of Traumatic Acute Subdural Hematoma Patients
}

Omar Youssef, Taher M. Ali, Khaled Anbar, Osama El-shahawy, Abdelrhman Enayet

Department of Neurosurgery, Faculty of Medicine, Cairo University, Cairo, Egypt

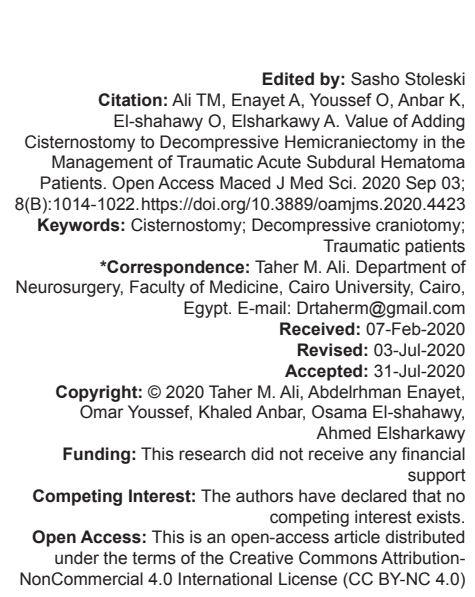

\section{Introduction}

Acute subdural hematoma (ASDH) occurs in up to one-third of patients with severe traumatic brain injury and has been associated with high mortality rate ranging 40-60\% and functional recovery ranging from 19 to $45 \%$ [1]. Decompressive hemicraniectomy (DHC) has remained the mainstay of surgery with the aim of decreasing intracranial pressure and thus prevented and treated this herniation. Although $\mathrm{DHC}$ brings the intracranial pressure to atmospheric pressure, it does not counteract the intracerebral pressure, which causes severe brain swelling and herniation [2]. Cisternostomy was introduced by Cherian I and his colleagues as a technique that helps to reduce the intracranial pressure in traumatic ASDH cases [3].

\section{Patients and methods}

A prospective randomized controlled study was designed to evaluate the value of adding cisternostomy to decompressive craniotomy in traumatic acute subdural hematoma patients.

Patients who presented to Cairo University Hospital emergency department and diagnosed with traumatic acute subdural hematoma matching our inclusion criteria in the period between January 2018 and June 2019 were included in this study. Informed consent was taken from $1^{\text {st }}$ degree relatives of the patient after detailed explanation of the study was discussed with them. Forty patients were randomized by giving them successive numbers according to their order of presentation and then were allocated according to these numbers - into one of two groups (patients with odd numbers were allocated into the first 
group and those with even numbers were allocated into the second group, each group consisting of 20 patients). The first group patients were operated on by decompressive craniotomy plus cisternostomy, while the second group patients were operated on by decompressive craniotomy only.

\section{Inclusion criteria}

The following criteria were included in the study:

- $\quad$ Age from 12 to 65 years.

- Traumatic acute subdural hematoma.

- $\quad$ Glasgow Coma Scale $<10$.

- $\quad$ Thickness of hematoma $\geq 10 \mathrm{~mm}$ or midline shift $\geq 5 \mathrm{~mm}$.

\section{Exclusion criteria}

The following criteria were excluded from the study:

- $\quad$ Associated intracerebral contusions $\geq 1 \mathrm{~cm}$ or intraventricular hemorrhage.

- $\quad$ Patients with severe comorbidities.

After standard clinical management was done including primary and secondary surveys, pre-operative stabilization, surgery was done

- Patients were operated on by either decompressive craniotomy with duroplasty and hinged lax repositioning of bone flap (Group 2) or decompressive craniotomy and cisternostomy (Group 1) in the following manner:

- $\quad$ Supine position with head rotation $15^{\circ}$ to the contralateral side and neck extension aiming to put malar eminence in the upper most point. A question mark skin incision was done and a frontotemporoparietal craniotomy was performed. The sphenoid ridge resection was done until the orbitomeningeal arteries were encountered and dealt with.

- $\quad$ A dural opening was first done, parallel to the supraorbital ridge and extended posteriorly permitting evacuation of the acute subdural hematoma.

- $\quad$ After this, a large brain spatula placed on a cottonoid and suction was used to get into the interoptic cistern. This step was done very early after draining the subdural hematoma to avoid brain swelling that makes cisternostomy difficult.

- After draining CSF for few minutes, the microscope was brought in and the opticocarotid and lateral carotid cisterns were opened sharply.

- $\quad$ The membrane of Liliequist was approached and opened through the opticocarotid or the lateral carotid windows until viewing the terminal part of basilar artery with its branches.

- Irrigation was done, dural opening was extended more posteriorly and any significant residual hematoma was drained.

- $\quad$ Duroplasty was done and the bone flap was easily repositioned due to lax brain (but not tightly attached, i.e., hinged) without further complications (Figures 1 and 2).
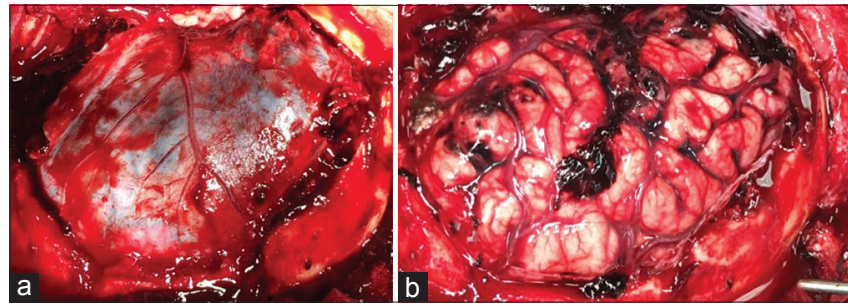

Figure 1: Decompressive craniotomy: (a) After bone flap elevation. (b) After opening of dura and hematoma evacuation, note brain herniation, hence the difficulty of bone flap replacement which was either replaced hinged or removed (craniectomy)

\section{Post-operative}

Serial clinical examinations and CT scans were performed postoperatively to assess patient's improvement after surgery. Outcome was assessed in the duration of 4 weeks postoperatively. Outcome assessment was done using Glasgow outcome scale with 1 denoting death and 5 denoting low disability.

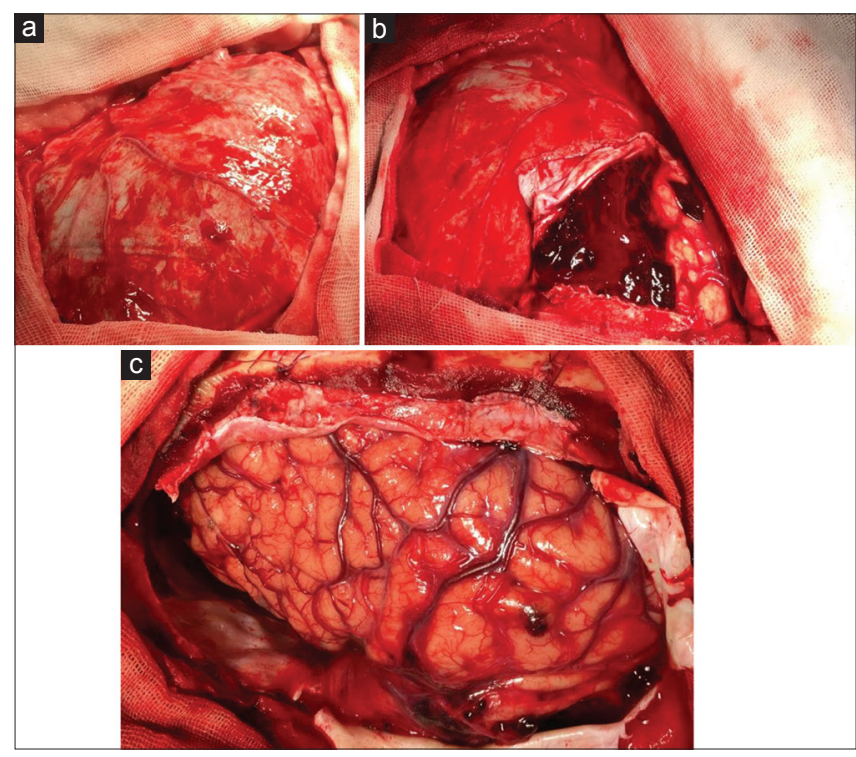

Figure 2: Decompressive craniotomy plus cisternostomy. (a) After bone flap removal. (b) Opening of dura. (c) After hematoma evacuation and cisternostomy, showing the lax brain, hence, bone flap was easily repositioned

\section{Statistical methods}

Data were coded and entered using the Statistical Package for the Social Sciences (SPSS) version 25 (IBM Corp., Armonk, NY, USA). Data were summarized 
using mean, standard deviation, median, minimum, and maximum in quantitative data and using frequency (count) and relative frequency (percentage) for categorical data. Comparisons between quantitative variables were done using the non-parametric Kruskal-Wallis and MannWhitney tests [4], [5]. For comparing categorical data, Chisquare $\left(\chi^{2}\right)$ test was performed. Exact test was used instead when the expected frequency is $<5$. Logistic regression was done to adjust for age and GCS as confounders in relation between mortality and surgery type [6]. $P<0.05$ was considered as statistically significant.

\section{Results}

1. Gender and Age: Table 1

Among the 40 patients, 35 were male $(87.5 \%)$ and 5 were female $(12.5 \%)$.

Table 1: Distribution of cases according to age

\begin{tabular}{lllll}
\hline & Mean & Standard deviation & Minimum & Maximum \\
\hline Overall age & 40.4 & 14.8 & 14 & 64 \\
$1^{\text {st }}$ group & 39.7 & 15.5 & 14 & 64 \\
$2^{\text {nd }}$ group & 41.2 & 14.3 & 17 & 64 \\
\hline
\end{tabular}

In the $1^{\text {st }}$ group: Males were 17 patients $(85 \%)$ and in the $2^{\text {nd }}$ group were $18(90 \%)$.

2. Glasgow Coma Scale on admission: Table 2

Table 2: Distribution of cases according to GCS

\begin{tabular}{llllll}
\hline & Median & Mean & Standard deviation & Minimum & Maximum \\
\hline Overall GCS & 6 & 6.2 & 1.8 & 4 & 9 \\
$1^{\text {st }}$ group & 5.5 & 6.1 & 2 & 4 & 9 \\
$2^{\text {nd }}$ group & 6 & 6.4 & 1.6 & 4 & 9 \\
\hline
\end{tabular}

3. Duration of surgery (In minutes):

Duration of surgery in the $1^{\text {st }}$ group was in average $175.5 \pm 17$ minutes while in the $2^{\text {nd }}$ group was $140 \pm 11.7$ with mean difference of 35.5 min (Figure 3).

Difference of operative time between the two groups was found to be significant $(p<0.001)$

\section{Outcome}

\section{Glasgow Outcome Score}

In our all included patients, median GOS was 2.5, in the $1^{\text {st }}$ group was 3 and in the $2^{\text {nd }}$ group was 1 (Table 3 ).

Difference of GOS between the two groups was not statistically significant $(p=0.341)$.

2. Mortality

Of all 40 patients, mortality occurred in 17 patients $(42.5 \%)$. Mortality in the $1^{\text {st }}$ group was 7 $(35 \%)$ while in the $2^{\text {nd }}$ group was $10(50 \%)$. Difference in mortality between two groups was not found to be significant $(p=0.337)$.

\section{Duration of ICU stay}

Mean duration of ICU stay in our 40 studied patients was found to be $9 \pm 6.5$ days, ranging from 2 to 25 days. Duration was in the $1^{\text {st }}$ group $7.8 \pm 7$ days while in the $2^{\text {nd }}$ group was $10.3 \pm 6$ days (Figure 4 ).

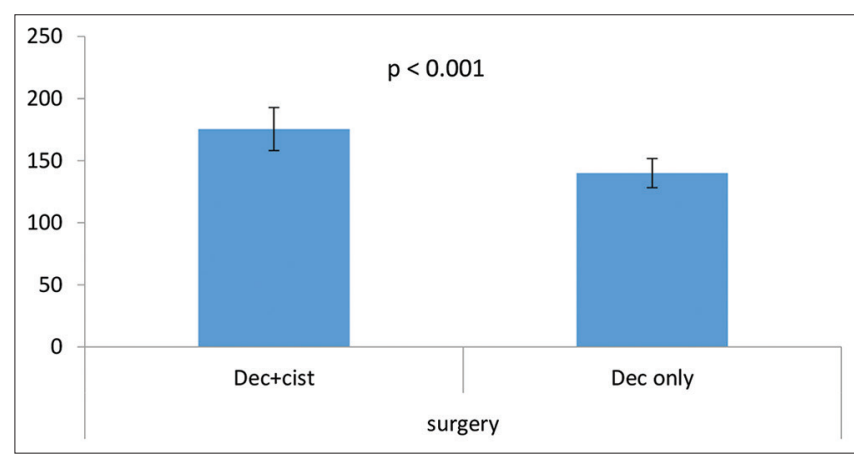

Figure 3: Duration of surgery in different groups

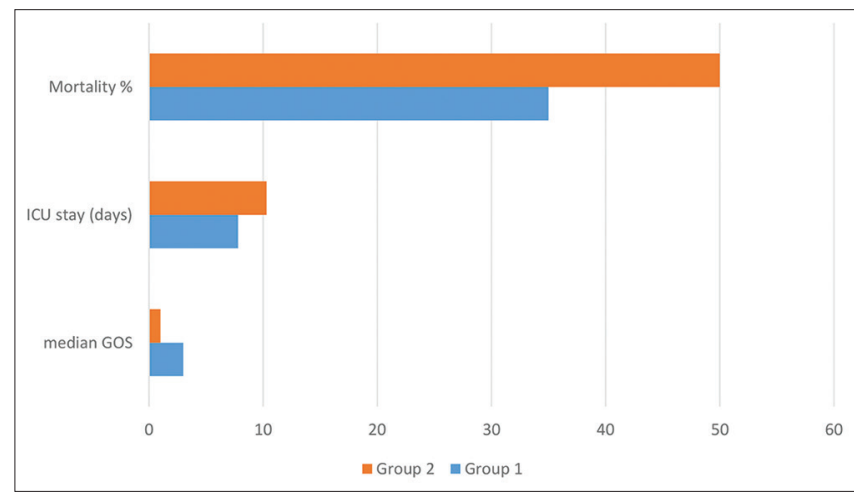

Figure 4: Comparison of results of Group 1 (DHC+Cisternostomy) and Group 2 ( $D H C$ only)

Difference between two groups was not found to be significant $(p=0.068)$.

Possible factors that were recorded in our study and found affecting primary outcome (mortality) and secondary outcome (Glasgow outcome score) were assessed. These factors were age and GCS on admission (Table 4)

1. Age

- In patients who survived, mean age was $35.4 \pm$ 13.7, while in those who died was 47.2 \pm 13.7 . Age was found to have significant effect on mortality $(p=0.011)$ (Figures 5 and Table 4).

- In addition, there was a significant difference of mortality rates in different age groups (Figure 6). Different age groups were also associated with difference of average Glasgow outcome score (Figure 7).

Table 3: Glasgow Outcome Score in different groups

\begin{tabular}{|c|c|c|c|c|c|c|c|c|c|c|c|}
\hline & \multicolumn{10}{|c|}{ Surgery } & \multirow[t]{3}{*}{$p$ value } \\
\hline & \multicolumn{5}{|c|}{ Dec+cist ( $1^{\text {st }}$ group) } & \multicolumn{5}{|c|}{ Dec only ( $2^{\text {nd }}$ group $)$} & \\
\hline & Mean & SD & Median & Minimum & Maximum & Mean & SD & Median & Minimum & Maximum & \\
\hline GOS & 2.95 & 1.67 & 3.00 & 1.00 & 5.00 & 2.40 & 1.73 & 1.00 & 1.00 & 5.00 & 0.341 \\
\hline
\end{tabular}


Table 4: Effect of age and GCS on mortality

\begin{tabular}{|c|c|c|c|c|c|c|c|c|c|c|c|}
\hline & \multicolumn{10}{|c|}{ Mortality } & \multirow[t]{3}{*}{$p$ value } \\
\hline & \multicolumn{5}{|c|}{ Survived } & \multicolumn{5}{|l|}{ Died } & \\
\hline & Mean & SD & Median & Minimum & Maximum & Mean & SD & Median & Minimum & Maximum & \\
\hline Age & 35.35 & 13.70 & 33.00 & 14.00 & 57.00 & 47.24 & 13.70 & 49.00 & 27.00 & 64.00 & 0.011 \\
\hline GCS & 6.87 & 1.71 & 7.00 & 4.00 & 9.00 & 5.35 & 1.50 & 5.00 & 4.00 & 9.00 & 0.006 \\
\hline
\end{tabular}

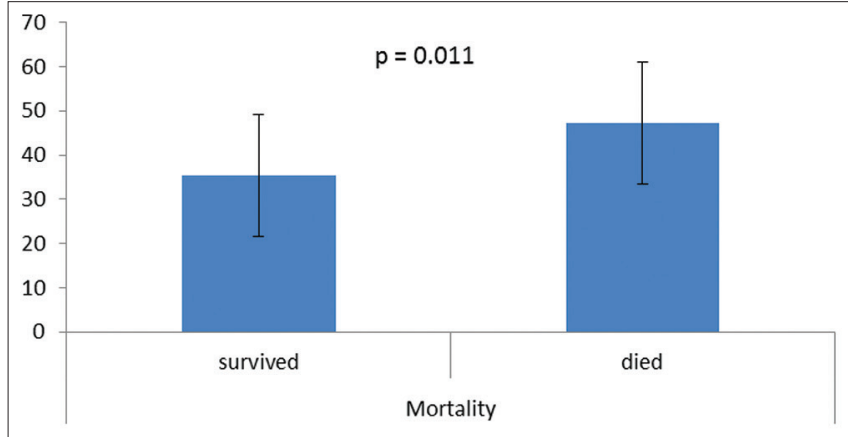

Figure 5: Mean age in patients who survived and in those who died

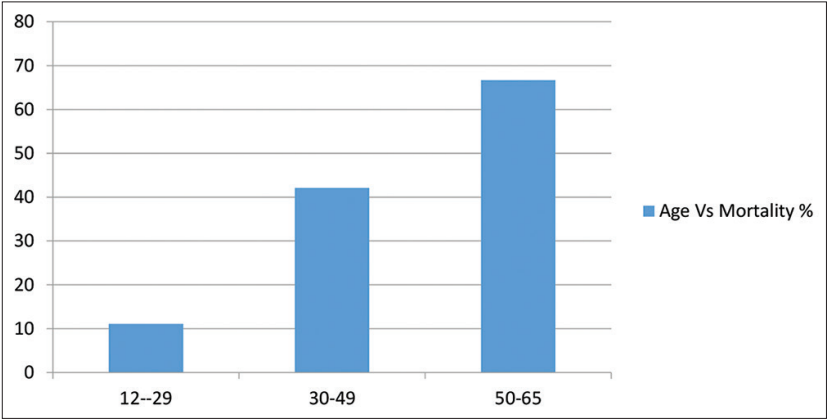

Figure 6: Mortality rates in different age groups

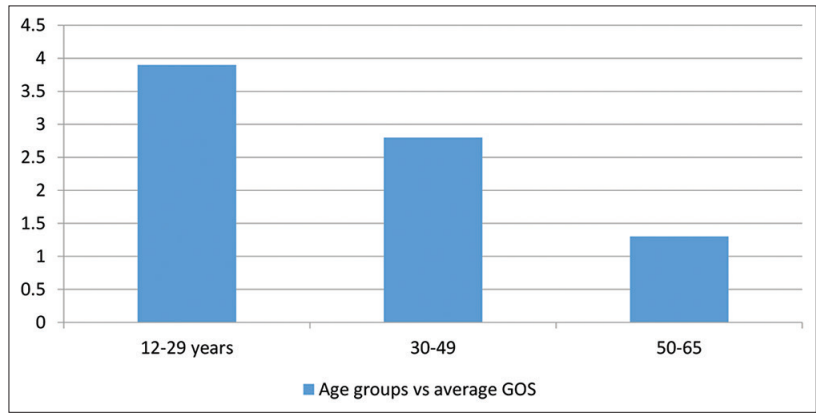

Figure 7: Average Glasgow Outcome Score in different age groups

2. Glasgow Coma Score on admission

- In patients who survived, median GCS on admission was 7, while in those who died was 5. GCS was found to have significant effect on mortality $(p=0.006)$ (Figure 8, Table 4).

- In addition, mortality rates were calculated in different Glasgow Coma Scales and are presented in Table 5 and Figure 9.

\section{Logistic regression was done with} mortality as dependent variable and surgery type as independent predictor adjusted for age and GCS (Table 6)

Type of surgery was found to have statistically insignificant outcome when outcome (mortality) was adjusted for age and GCS on admission.

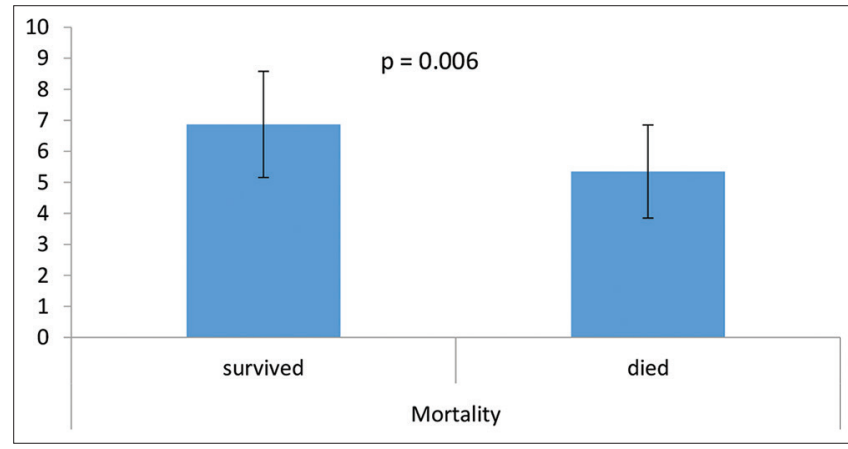

Figure 8: Relation between Glasgow Coma Scale on admission and mortality

Table 5: Relation between GCS on admission and mortality

\begin{tabular}{ll}
\hline GCS on admission & Mortality \% \\
\hline 4 & 75 \\
5 & 55.5 \\
6 & 42.9 \\
7 & 20 \\
8 & 25 \\
9 & 14.3 \\
\hline
\end{tabular}

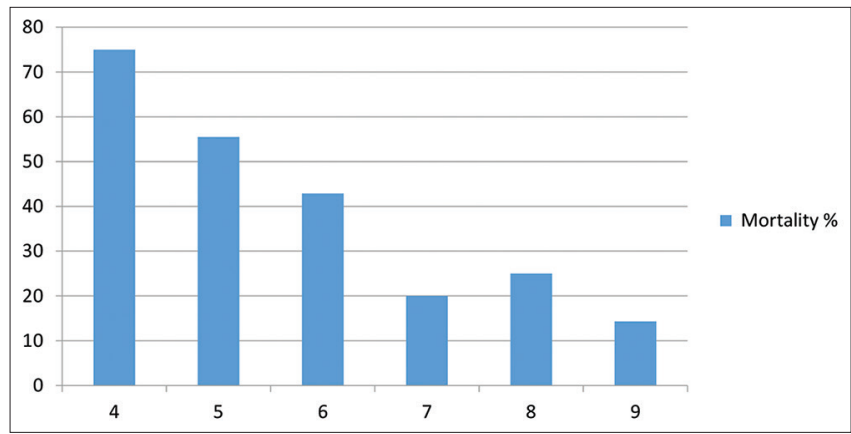

Figure 9: Mortality percent in different Glasgow Coma Scores

Table 6: Logistic regression

\begin{tabular}{llllll}
\hline & p value & OR & \multicolumn{2}{l}{$95 \%$ C.I. } \\
\cline { 4 - 5 } & & & Lower & Upper \\
\hline Death & Surgery (Dec+cist) & 0.216 & 0.356 & 0.069 & 1.827 \\
& Age & 0.018 & 1.076 & 1.012 & 1.143 \\
& GCS & 0.012 & 0.470 & 0.261 & 0.846 \\
\hline
\end{tabular}

\section{Case Presentation}

\section{Case 1}

Male patient 19 years old presented after motor car accident with GCS: 9 .

Brain CT scan revealed left frontoparietal acute subdural hematoma with thickness $1.1 \mathrm{~cm}$.

Operated on by the left decompressive craniotomy PLUS cisternostomy.

After surgery, the patient was obeying and extubated followed by complete recovery (fully conscious) 2 days after surgery (GOS: 5 ) (Figures 10 and 11). 


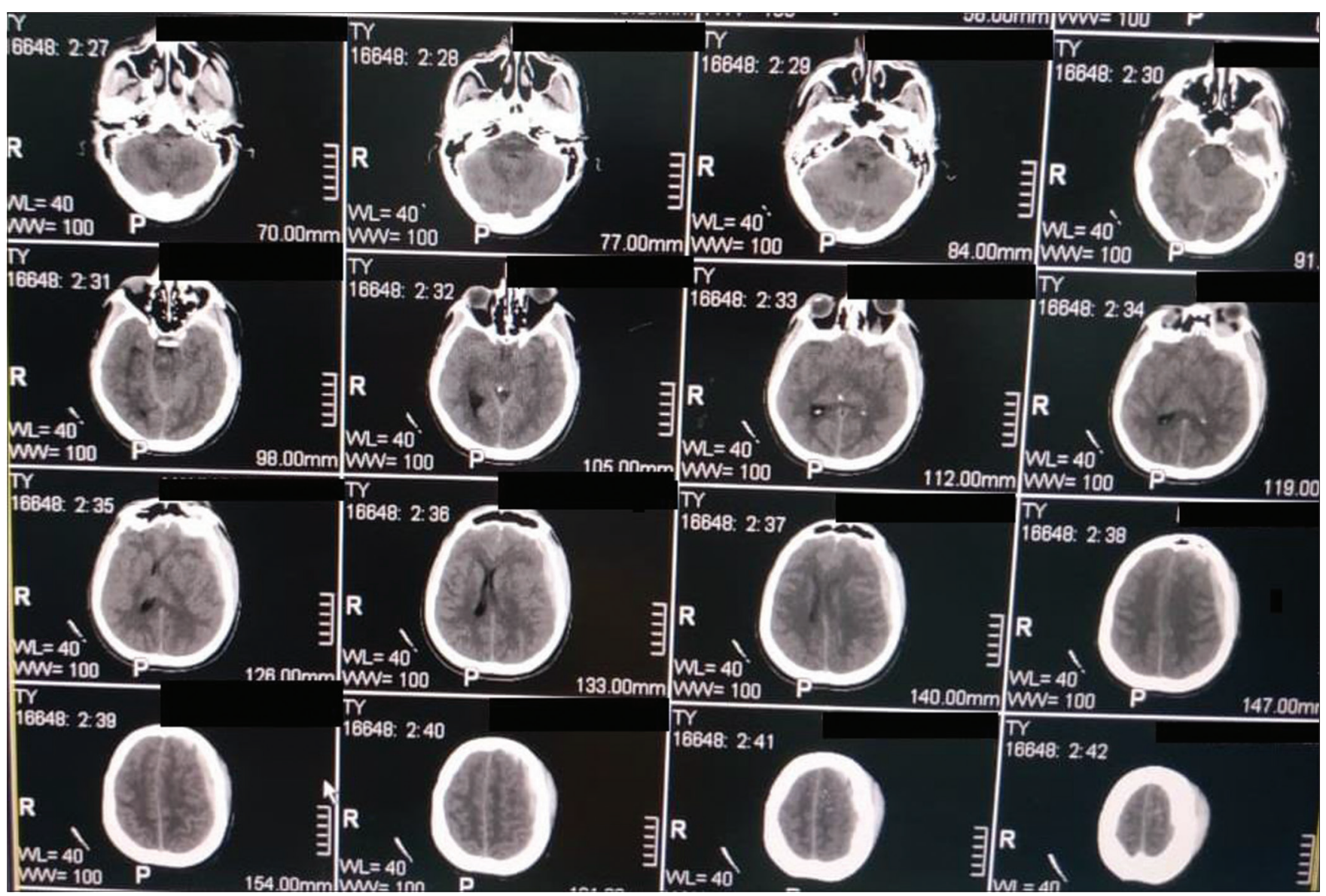

Figure 10: Pre-operative computed tomography of case 1 showing left frontoparietal acute subdural hematoma

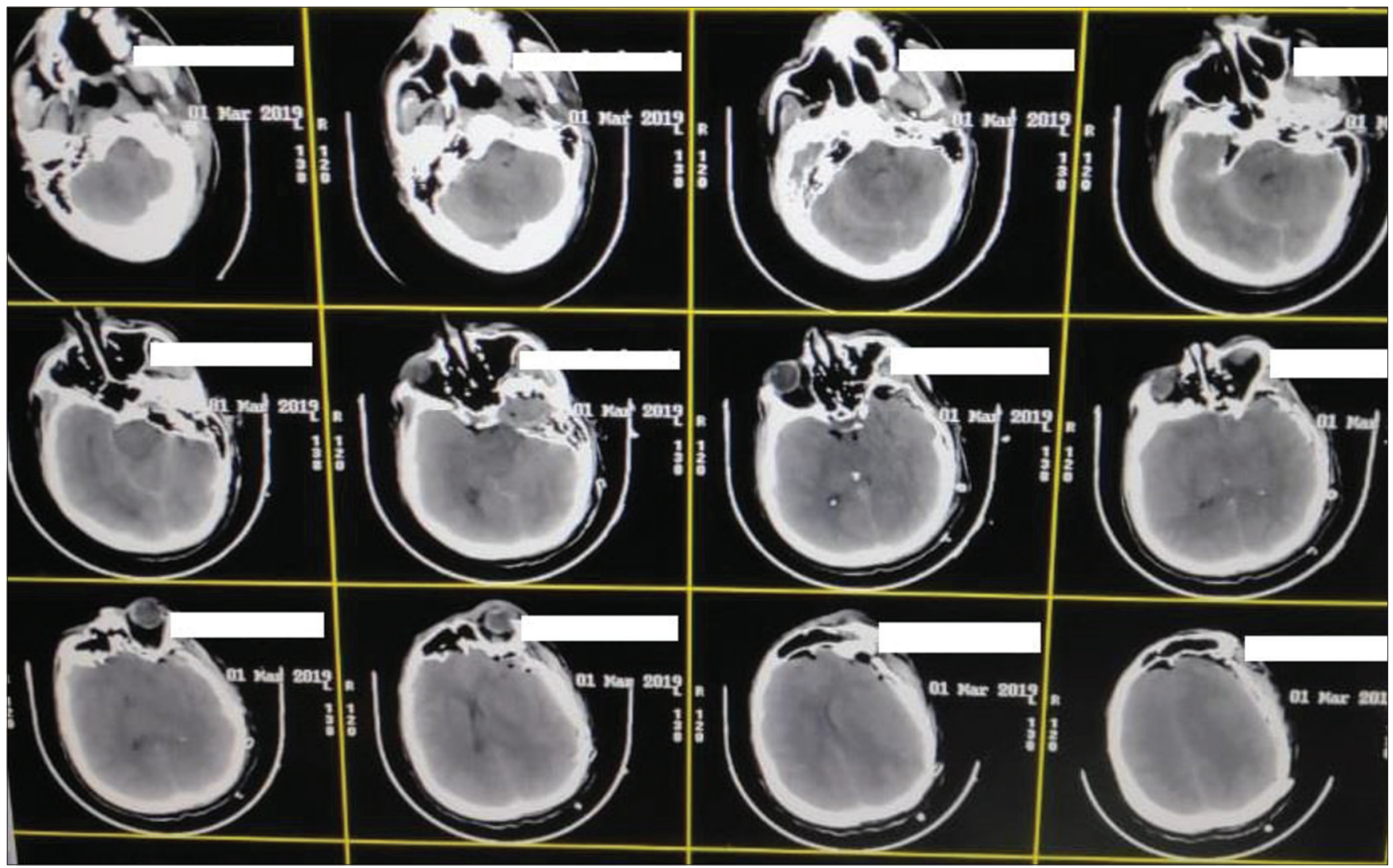

Figure 11: Post-operative computed tomography of case 1 showing hematoma evacuation and lax brain 


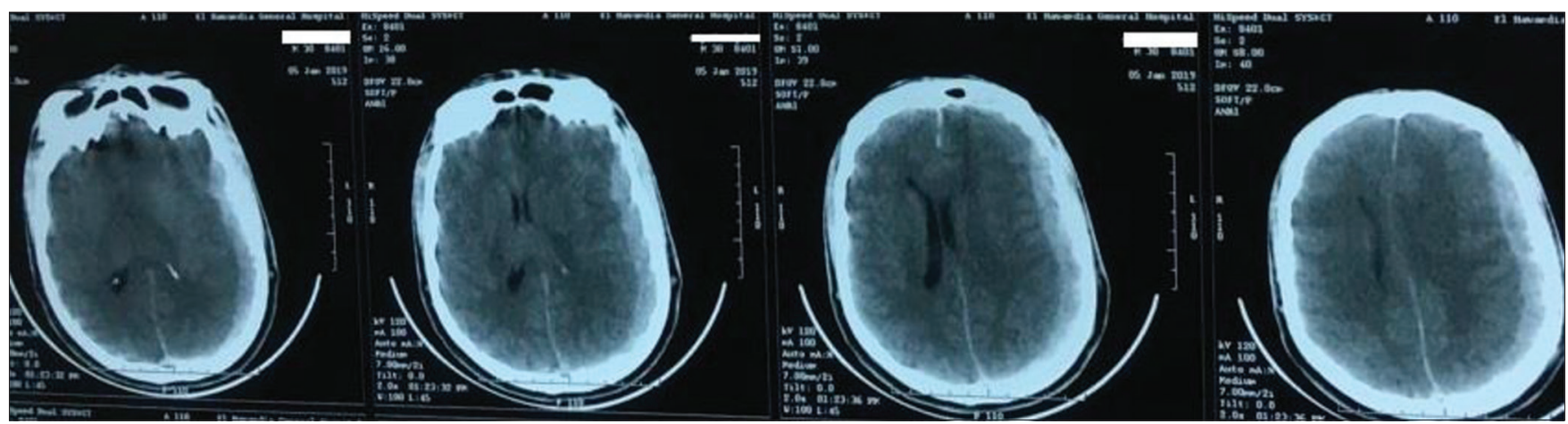

Figure 12: Pre-operative computed tomography of case 2 showing left frontoparietal acute subdural haematoma

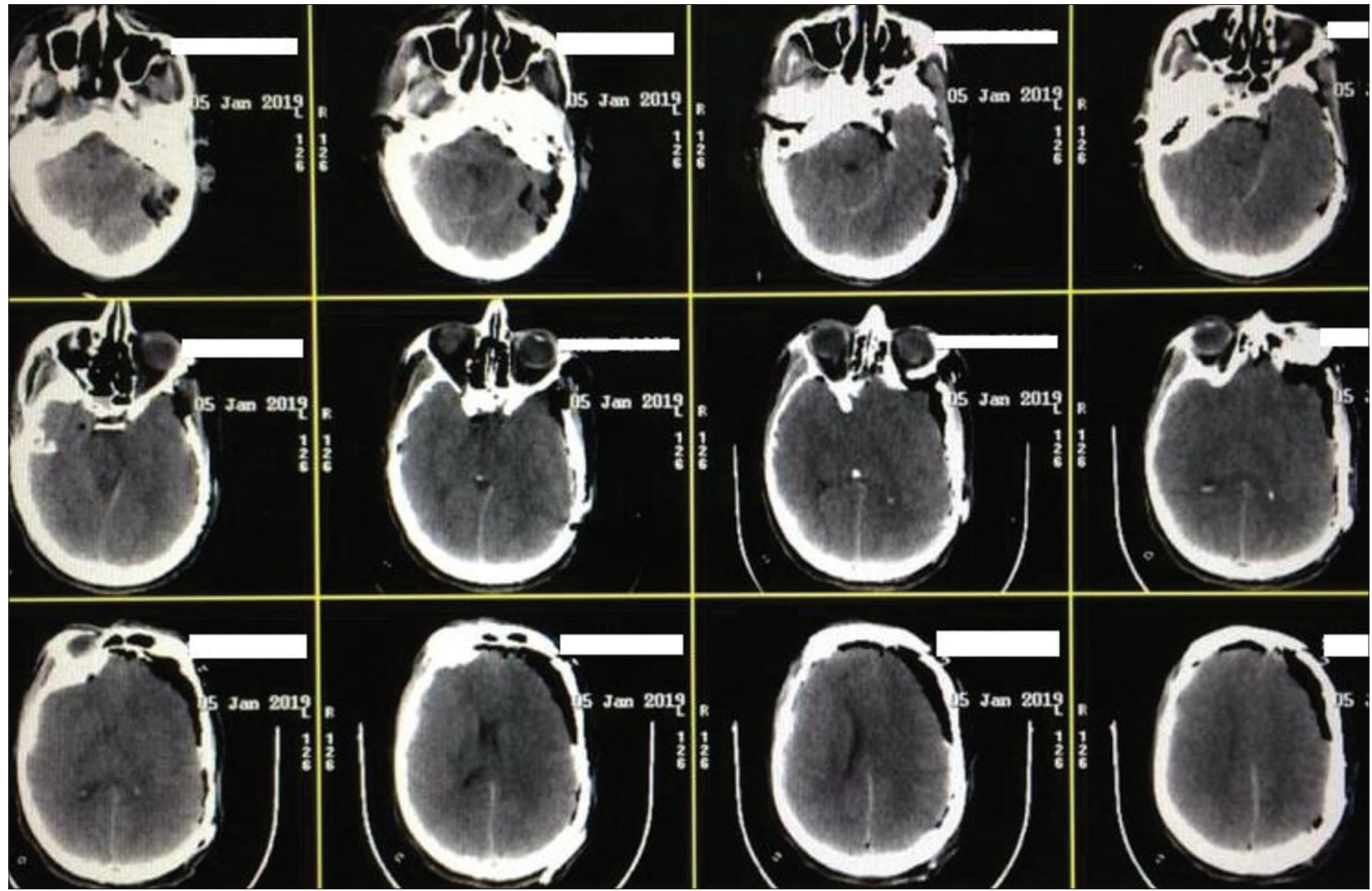

Figure 13: Post-operative computed tomography brain of case 2 done $24 \mathrm{~h}$ after surgery showing hematoma evacuation with lax brain

\section{Case 2}

- $\quad$ Male patient 40 years old presented after motor car accident with GCS: 8 and right-sided hemiparesis.

- $\quad$ Brain CT showed left frontoparietal acute subdural hematoma with thickness $1.3 \mathrm{~cm}$ and midline shift $1 \mathrm{~cm}$ operated on by decompressive craniotomy PLUS cisternostomy.

- $\quad$ Patient was obeying 1 day after surgery and extubated. The patient was discharged 5 days later, fully conscious with right-sided hemiparesis G IV (GOS: 4) (Figures 12-14).

\section{Case 3}

- $\quad$ Female patient 32 years old presented after fall from height with GCS: 9
- $\quad$ CT scan revealed right frontoparietal acute subdural hematoma of $1 \mathrm{~cm}$ with midline shift $0.6 \mathrm{~cm}$

- Patient was operated on by the right decompressive craniotomy with evacuation of hematoma PLUS cisternostomy.

- $\quad$ Patient improved and became fully conscious after 2 days (GOS 5) (Figures 15 and 16).

\section{Discussion}

For more than 1 century, tailored decompressive hemicraniectomy (DHC) has been used for the treatment of lesions of the brain with varying success in patients with TBI. 


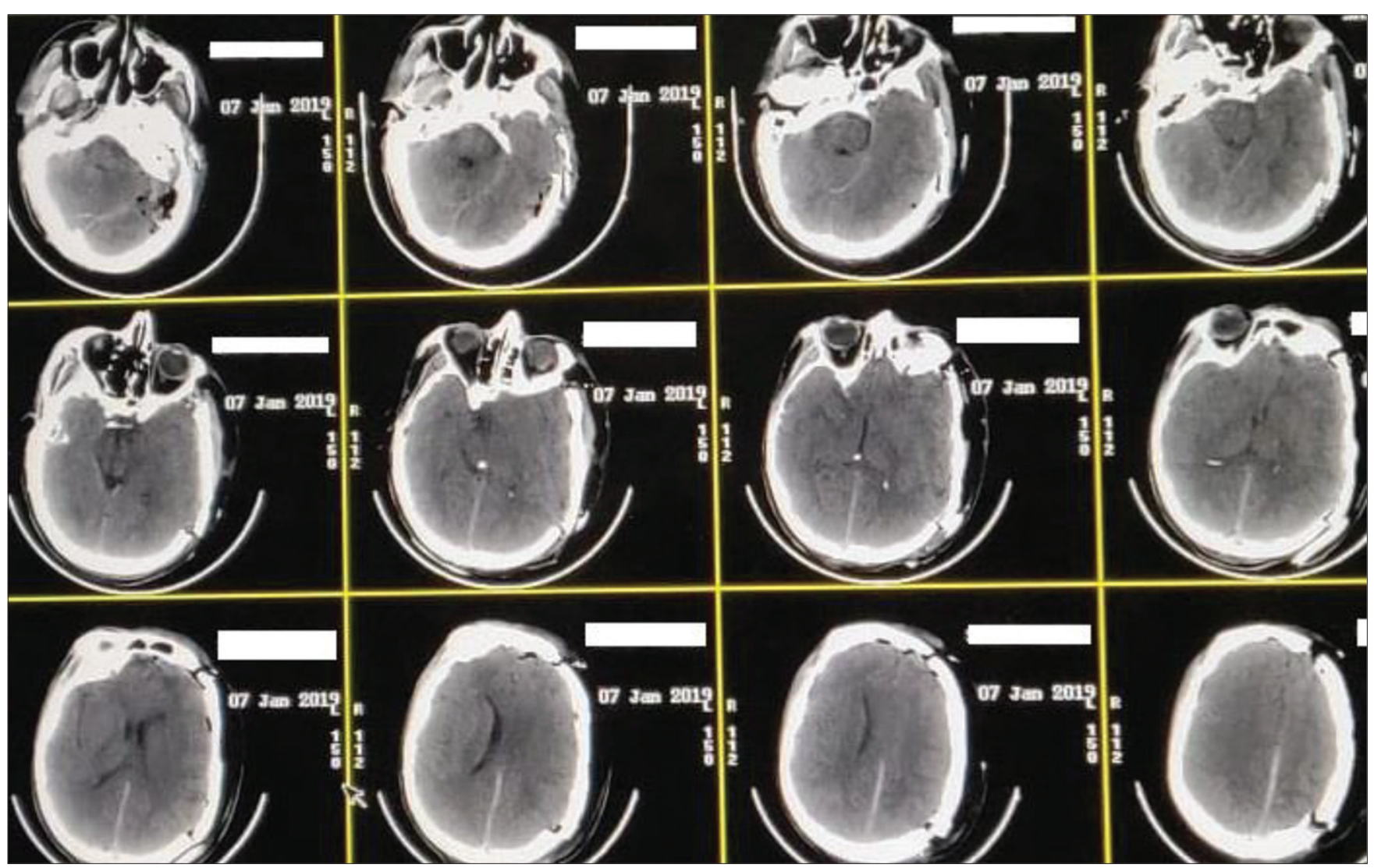

Figure 14: Post-operative computed tomography brain done $72 \mathrm{~h}$ after surgery showing evacuation of hematoma and lax brain

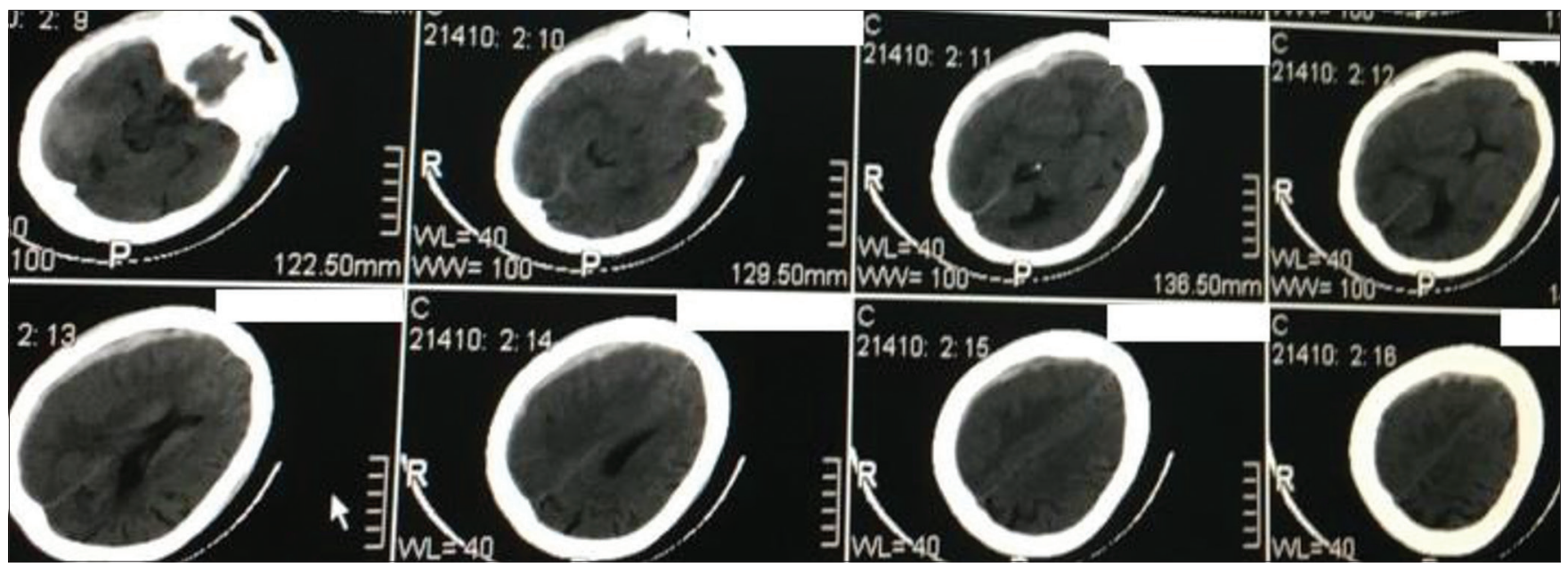

Figure 15: Pre-operative computed tomography brain of case 3 showing left-right frontoparietal acute subdural hematoma

The wide variation in practice between different continents, countries, and even within departments is a reflection of the lack of high-quality evidence and clear guidelines for this condition. Accordingly, DHC is carefully recommended as a possible option for selected patients. This urged the investigators to search for other management strategies for this condition. Cherian et al. stated that that the traumatic cerebral edema may be due to egress of CSF from the cisternal space into the brain parenchyma through the VR spaces. In DHC, removal of bone helps to reduce intracranial pressure, but on the expense of external cerebral herniation and its effect on CSF and hemodynamic flow changes. Cisternostomy opens the basal cisterns to atmospheric pressure and causes a "back-shift" of CSF through the Virchow Robin (VR) spaces, thus reducing the intraparenchymal brain pressure (7).

To the best of our knowledge, Cherian et al. were the first to introduce the concept of cisternostomy in traumatic brain injury with the first and largest study till moment in the study that they published in 2013. Cherian et al. study was started in 2007 and was conducted in a stepwise manner since the surgeon modified the existing treatment for severe head injury 


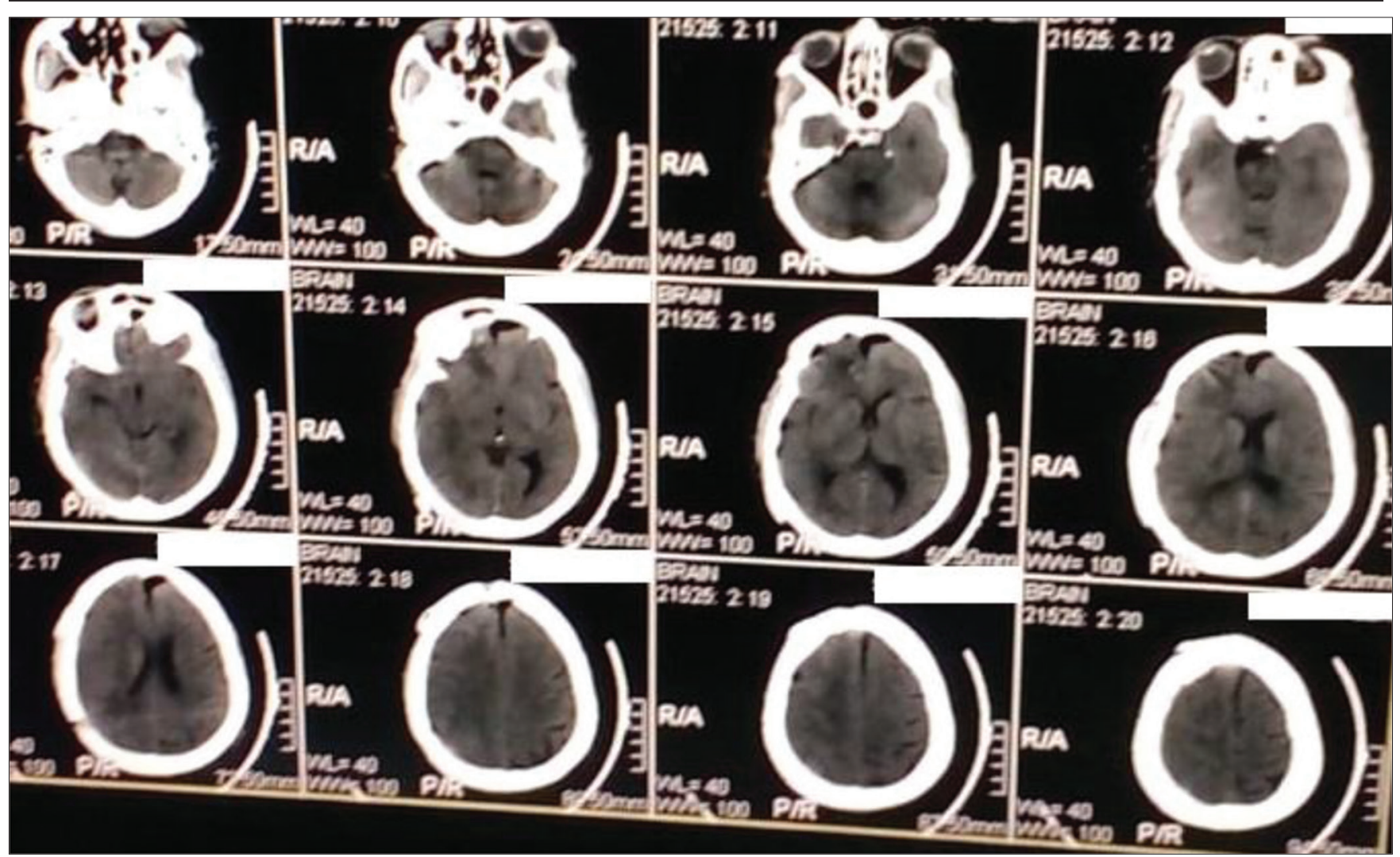

Figure 16: Post-operative computed tomography brain of case 3 showing evacuation of hematoma

with the addition of cisternostomy first and after analyzing the results, cisternostomy was used as a substitute for DHC [7].

The value of adding cisternostomy to DHC can be concluded when comparing the high mortality rates of DHC alone which was $50 \%$ in our study. This goes in hand with the mortality in Haselberger study where mortality was $51.35 \%$ [8]. Furthermore, in Rush et al. study, mortality rates were $32 \%$ in 1763 patients who underwent decompressive craniectomy [9]. Mortality rates decreased in our study to reach $35 \%$ when cisternostomy was added to DHC

This difference in mortality rates between two groups was not found to be statistically significant ( $p=0.337$ ). Furthermore, after doing logistic regression with mortality as dependent variable and surgery as independent predictors adjusted for age and Glasgow Coma Scale (GCS); cisternostomy did not add statistically significant improvement of mortality rate ( $p=0.216)$. Median Glasgow outcome score (GOS) was also better when adding cisternostomy to DHC when compared to DHC alone, but it also was not statistically significant $(p=0.341)$.

When comparing our results with the results published by Cherian et al., mortality was $26.4 \%$ in his first group (DHC + cisternostomy), 34.8\% in his second group (DHC only). In their study, they had a third group in which they did cisternostomy only without decompressive craniotomy and mortality was $15.6 \%$ in this third group. Furthermore, mean GOS improved from 2.8 (when doing $\mathrm{DHC}$ only) to 3.9 when adding cisternostomy [7].

The reason of our study did not show that statistically significant difference of mortality rates or GOS could be attributed to the small number of patients. Furthermore, in Cherian et al. study, important prognostic factors (as age and average GCS on admission) were not mentioned in that study which may be the cause of the difference [7].

The added value of cisternostomy should be looked in the context that it neither added burden on patient nor added much increase in operative time as in our study; in the $1^{\text {st }}$ group (DHC+ cisternostomy), duration was in average $175.5 \pm 17 \mathrm{~min}$ while in the $2^{\text {nd }}$ group (DHC only) was $140 \pm 11.7$. Mean difference of operative time between the two groups in our study was $35.5 \mathrm{~min}$ as compared to Cherian et al. study, where this time (after the learning curve) was 20 min [10].

Another value that we found was shorter ICU stay as in our study it was $7.8 \pm 7$ days in the $1^{\text {st }}$ group (DHC + cisternostomy) and $10.3 \pm 6$ days in the $2^{\text {nd }}$ group of patients (DHC only). Difference between two groups was not found to be statistically significant $(p=0.068)$ which can also be attributed to the small number of patients.

This coincides with the results of Cherian et al. study, where mean ventilator days for the three groups were $6.3,3.2$, and 2.4 days in the first (DHC+Cisternostomy), second (DHC only), and third (cisternostomy only) groups, respectively. 
In our study, when age and GCS on admission were assessed as prognostic indicators:

Age was found to have significant effect on mortality $(p=0.011)$ and there was significant difference of mortality rates in different age groups $(p=0.042)$. In general, younger age groups were associated with better GOS. This coincides with Koç et al. results, mortality was $63 \%$ in younger patients (below 60 years) and $73 \%$ in patients aged above 60 years [10].

GCS on admission was found to have significant effect on mortality ( $p=0.006)$. In general, lower GCS on admission was associated with worse GOS. This coincides with Koç et al. study, in which mortality was $95 \%$ in patients with GCS of $3-4,79 \%$ in GCS 5-6, and 44\% in GCS 7-8. They had no mortality in patients with higher GCS [10].

Regarding the feasibility of subfrontal retraction in these cases, we agree with Cherian et al. that a basal approach and using the "2 min window" one gets after removing the subdural hematoma does help to get into the interoptic cistern. Once that cistern is opened and CSF drains, the brain swelling comes down significantly and surgeon can then bring the operative microscope at ease to complete the cisternostomy. We did not have cases of failed cisternostomy due to herniated brain and we did not need to do frontal lobectomy in any case to reach the interoptic cistern. We also believe that there is no need to do a formal decompressive craniotomy when doing cisternostomy as the intracranial pressure dropped obviously after performing it and a smaller trauma flap that just gives access to evacuation of hematoma is sufficient. Furthermore, there is no need to do duroplasty or remove the bone flap which is also the result that Cherian et al. reached and lead them to do cisternostomy alone in their study [7].

Whether the tension remained low after surgery or increased few days later is still a matter of question and needs accurate measurement through continuous pre- and post-operative ICP monitoring which we did not have. A major limitation in our study is the relatively low number of patients compared to the study published by Cherian et al. study which prevents us from generalization of our results or producing practice guidelines, however, it opens the door for further larger clinical trials in that new management modality.

\section{Conclusion}

Adding cisternostomy to decompressive craniotomy in traumatic acute subdural hematoma treatment had many values that were evident by better outcome (but not statistically significant) in the form of lower mortality rate, better Glasgow outcome scores, and shorter ICU stay. Whether it should replace the routine decompressive craniotomy in these cases or not need further larger clinical trials.

\section{References}

1. Li LM, Kolias AG, Guilfoyle MR, Timofeev I, Corteen EA Pickard JD, et al. Outcome following evacuation of acute subdural haematomas: A comparison of craniotomy with decompressive craniectomy. Acta Neurochir (Wien). 2012;154(9):1555-61. https://doi.org/10.1007/s00701-012-1428-8

PMid:22752713

2. Chi JH. Craniectomy for traumatic brain injury: Results from the DECRA trial. Neurosurgery. 2011;68(6):N19-20. https://doi. org/10.1227/01.neu.0000398210.58112.7e

PMid:21778945

3. Cherian I, Bernardo A, Grasso G. Cisternostomy for traumatic brain injury: Pathophysiological mechanisms and surgica technical notes. World Neurosurg. 2016;89:51-7. https://doi. org/10.1016/j.wneu.2016.01.072

PMid:26851743

4. Iliff JJ, Wang M, Liao Y, Plogg BA, Peng W, Gundersen GA, et al. A paravascular pathway facilitates CSF flow through the brain parenchyma and the clearance of interstitial solutes, including amyloid $\beta$. Sci Transl Med. 2012;4(147):147ra111. https://doi. org/10.1126/scitransImed.3003748 PMid:22896675

5. Chan YH. Biostatistics 102: Quantitative data parametric and non-parametric tests. Singapore Med J. 2003;44(8):391-6. PMid:14700417

6. Chan YH. Biostatistics 202: Logistic regression analysis Singapore Med J. 2004;45(4):149-53

PMid:15094982

7. Cherian I, Yi G, Munakomi S. Cisternostomy: Replacing the age old decompressive hemicraniectomy? Asian J Neurosurg. 2013;8(3):132-8. https://doi.org/10.4103/1793-5482.121684 PMid:24403955

8. Hasselberger K. Prognosis after acute subdural and epidura hemorrhage. Acta Neurochir (Wien). 1988;90(3-4):111-6. https:// doi.org/10.1007/bf01560563 PMid:3354356

9. Rush B, Rousseau J, Sekhon MS, Griesdale DE. Craniotomy versus craniectomy for acute traumatic subdural hematoma in the United States: A national retrospective cohort analysis. World Neurosurg. 2016;88:25-31. https://doi.org/10.1016/j. wneu.2015.12.034 PMid:26748175

10. Koç RK, Akdemir H, Oktem IS, Meral M, Menkü A. Acute subdura hematoma: Outcome and outcome prediction. Neurosurg Rev. 1997;20(4):239-44. https://doi.org/10.1007/bf01105894 PMid:9457718 